\title{
Spatial interactions between marine predators and their prey: herring abundance as a driver for the distributions of mackerel and harbour porpoise
}

\author{
Signe Sveegaard ${ }^{1, *}$, Jacob Nabe-Nielsen $^{1}$, Karl-Johan Stæhr ${ }^{2}$, Torben Filt Jensen ${ }^{2}$, \\ Kim N. Mouritsen ${ }^{1,3}$, Jonas Teilmann ${ }^{1}$ \\ ${ }^{1}$ Department of Bioscience, Aarhus University, Frederiksborgvej 399, 4000 Roskilde, Denmark \\ ${ }^{2}$ DTU Aqua, National Institute of Aquatic Resources, Technical University of Denmark, Nordsøen Forskerpark, Postboks 101, \\ 9850 Hirtshals, Denmark \\ ${ }^{3}$ Marine Ecology, Department of Bioscience, Aarhus University, Ole Worms Allé 1, 8000 Aarhus C, Denmark
}

\begin{abstract}
The distribution of marine predators is tightly coupled with that of their prey, and may also be affected by interactions between competing predators. In order to adopt an ecosystem approach to the management of a species, it is essential to understand these processes. In this study, we examined whether the distributions of 2 marine predators, harbour porpoise Phocoena phocoena and mackerel Scomber scombrus, are related to the distribution of a major prey species, herring Clupea harengus, on a large spatial scale. Porpoise distribution data were obtained from satellite-tracked harbour porpoises (1998 to 2009), while mackerel and herring distribution data were found by the annual ICES acoustic herring surveys providing data with overlapping temporal and spatial scales (2000 to 2009). We found that the 3 species were not evenly distributed within the study area and that harbour porpoise distribution was best explained solely by the distribution of herring, while herring together with depth explained $50 \%$ of the mackerel distribution. These results underline the importance of an ecosystem approach in management plans for predatory species by including monitoring and management of main prey species.
\end{abstract}

KEY WORDS: Clupea harengus - Scomber scombrus · Phocoena phocoena - Satellite tracking · Acoustic survey $\cdot$ Cetacean $\cdot$ Mantel test $\cdot$ Hurdle model $\cdot$ GLM

Resale or republication not permitted without written consent of the publisher

\section{INTRODUCTION}

In recent years, the focus on ecosystem management has increased, and the spatio-temporal dynamics of predator-prey interactions have been incorporated more frequently in studies of species abundance and distribution (Williams et al. 2004). The effects of these interactions are scale dependent. At small spatial scales, anti-predatory behaviour will dominate, while at larger scales prey species often congregate in areas with favourable environmental conditions regardless of whether predators are present (Rose \& Leggett 1990). In the marine environment, pelagic fish species often aggregate in large schools to avoid predation. The abundance of such schools is frequently related to mesoscale oceanographic features such as eddies and fronts (e.g. Swartzman et al. 1994, Maravelias et al. 1996), making areas with high prey abundances predictable for the predators.

Atlantic herring Clupea harengus are schooling fish with long annual migrations between their feeding and spawning areas. The largest stock relevant for this study, the Baltic Sea Spring Spawning (BSSS) herring, spawn in the early spring near the island of Rügen (Germany) in the western Baltic, after which they migrate north through the deep waters of the Skagerrak to feed in the north-eastern 
North Sea. In the summer, they migrate back through the Skagerrak and Kattegat and spend the winter in the Sound and the Great Belt before the next spawning period (Nielsen et al. 2001). Herring serve as prey for several species, including mackerel Scomber scombrus and harbour porpoise Phocoena phocoena. The factors that drive the distribution of these species are not well understood, although the distribution of the harbour porpoise has been suggested to be tightly linked to that of its prey (Read \& Westgate 1997, Koopman 1998). This hypothesis has rarely been tested due to lack of data on prey abundance on a sufficiently fine spatial and temporal scale (Santos \& Pierce 2003), and the available results are inconsistent (Palka 1995, Sveegaard et al. 2012). The hypothesis has also been tested indirectly by modelling porpoise distribution in relation to environmental factors that serve as proxies for prey distribution (e.g. Marubini et al. 2009, Edrén et al. 2010, Embling et al. 2010, Gilles et al. 2011). Here, depth, distance to coast, current, temperature, sediment type and proxies for primary production and fronts (chlorophyll and nutrients) were found to be associated with harbour porpoise distribution, although the subset of influential variables varied both spatially and temporally. This may be consistent with variation in prey preferences of harbour porpoises (Benke et al. 1998). In the Kattegat and Skagerrak, harbour porpoises predominately prey on herring, cod, gobies and sandeels, and herring contribute 46 to $55 \%$ of the weight of the diet (Aarefjord et al. 1995, Börjesson et al. 2003). Mature herring (25 to $30 \mathrm{~cm}$ ) may contain up to twice the energy density of other major prey species like cod (Lawson et al. 1998, Spitz et al. 2010), which may explain their importance to porpoises.

Atlantic mackerel is a fast swimming, pelagic schooling species. The North Sea holds a distinct stock that overwinters in deeper parts of the Skagerrak and north-eastern North Sea from where it ascends to the surface waters in spring (Postuma 1965, Hamre 1978). Spawning takes place in midMay to late June in the central North Sea and to a lesser degree also in the Skagerrak and Kattegat (ICES 2009). After spawning, mackerel redistribute in the North Sea or migrate into neighbouring coastal waters such as the Skagerrak, Kattegat, the Sound, the Belt Sea and the western Baltic Sea (Jansen \& Gislason 2011). Here, they prey on small herring $(<10 \mathrm{~cm})$ and zooplankton (Dahl \& Kirkegaard 1986). Mackerel are rarely consumed by harbour porpoises (Aarefjord et al. 1995, Börjesson et al. 2003).
In this study, we tested whether the distributions of Atlantic mackerel and harbour porpoises are related to the distribution of a major prey species, Atlantic herring, in the eastern North Sea, Skagerrak and Kattegat.

\section{MATERIALS AND METHODS}

\section{Study area}

The study area covers $60642 \mathrm{~km}^{2}$ north of $56^{\circ} \mathrm{N}$ and east of $6^{\circ} \mathrm{E}$ (the eastern North Sea, Skagerrak and Kattegat; Fig. 1). It stretches over a varied bathymetry with relatively shallow water $(<50 \mathrm{~m})$ in the Kattegat and the southern Skagerrak, and deeper waters $(\sim 700 \mathrm{~m})$ in the Norwegian Trench in the Northern Skagerrak. The study area was divided into grid cells of $0.25^{\circ} \mathrm{N} \times 0.5^{\circ} \mathrm{E}\left(\sim 870 \mathrm{~km}^{2}\right.$, equivalent to a quarter of an ICES square). This is the smallest grid size available to allow the acoustic surveys to pass through each grid cell.

\section{Fish density}

Herring and mackerel densities were calculated from 10 annual ICES coordinated acoustic herring surveys taking place in the first $2 \mathrm{wk}$ of July (2000 to 2009). The survey track lines differed slightly annually but were ca. 1950 nautical miles (n miles) every year. Tracks were designed to enter all ICES squares within the study area (Fig. 1). The design of the acoustic herring surveys was described by Simmonds et al. (1996). In short, the strategy was to cover the largest possible number of depth zones within each geographical stratum. Acoustic data were recorded continuously, and fish densities were subsequently calculated with a sampling unit of $1 \mathrm{n}$ mile. Pelagic and demersal trawl hauls for the species identification were carried out between 10:00 and 15:00 and between 20:30 and 03:00 h UTC, usually with 2 day-hauls (mostly demersal) and 2 night-hauls (mostly pelagic). One-hour hauls were used as a standard during the survey, but were sometimes shortened if the catch was large.

During surveys, the length groups, number of individuals and total weight per fish species were recorded. Mean \pm SD length of herring was $20.5 \pm$ $0.55 \mathrm{~cm}$, with $95 \%$ between 15 and $30 \mathrm{~cm}$; mackerel were $28.6 \pm 0.58 \mathrm{~cm}$ long, with the majority $(89 \%)$ being 20 to $30 \mathrm{~cm}$. Numbers of herring (HER) and mackerel (MAC) per sampling unit (1 $\mathrm{n}$ mile) were pooled within each grid cell and subsequently aver- 


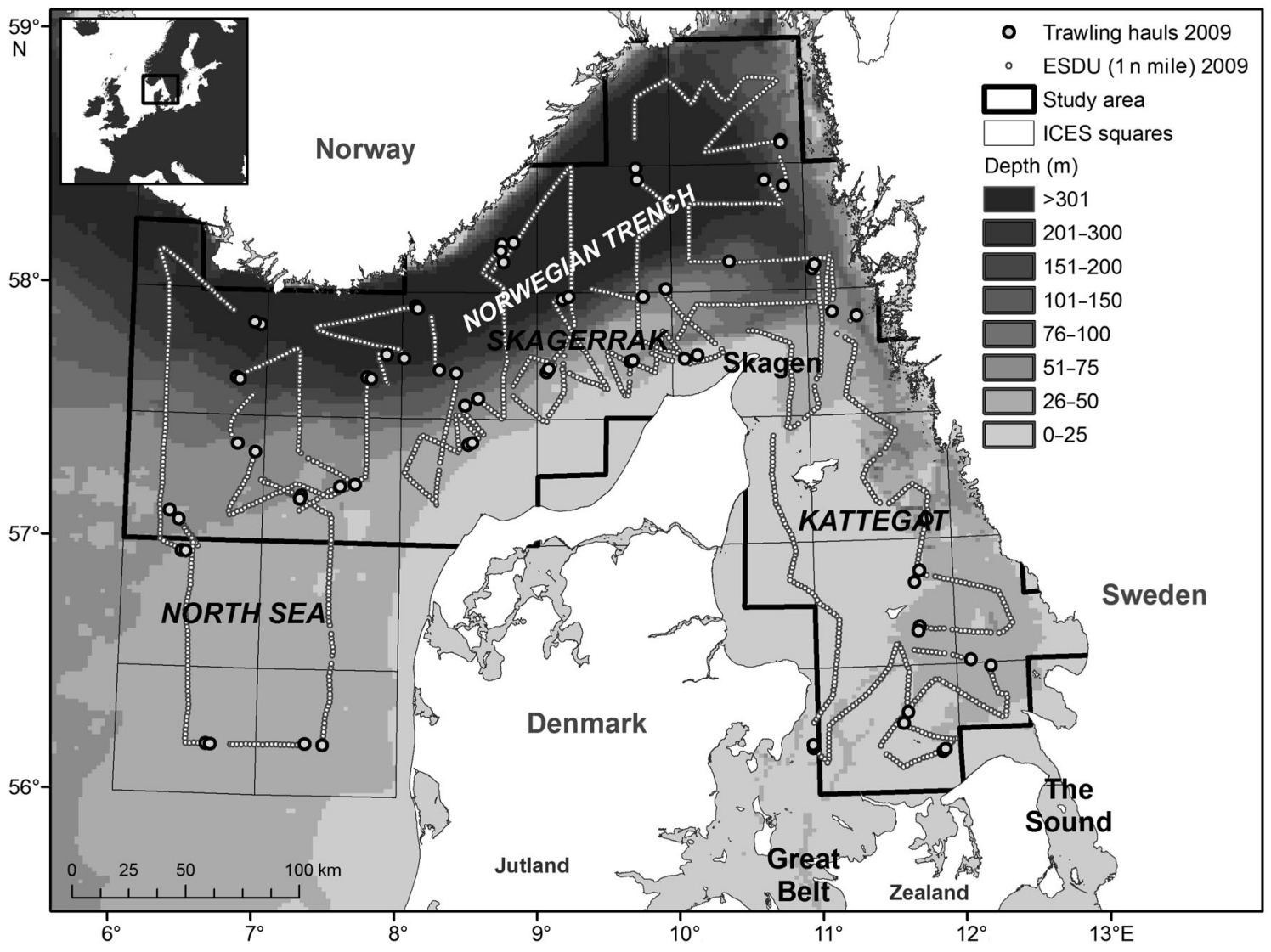

Fig. 1. Study area in the Skagerrak and Kattegat. The bold line encompasses the area with data for herring, mackerel and harbour porpoise. ICES squares are indicated, as well as an example of the acoustic herring survey transects (ESDU: Elementary Sampling Distance Unit = 1 nautical mile) and trawl hauls in July 2009

aged. To study the mackerel-herring relationship, the average length distributions (2006 to 2009) of herring and mackerel were calculated.

\section{Harbour porpoise data}

We included all porpoise locations around the time of the acoustic fish surveys from June to August, which resulted in a total number of 508 locations (1 location porpoise ${ }^{-1} \mathrm{~d}^{-1}$ ) transmitted by 34 harbour porpoises tagged from 1998 to 2010. Of these, 17 were tagged near Skagen and 17 were tagged along the eastern coast of Jutland and along the shores of Funen and Zealand (Fig. 1). For the tagging procedure and tag settings, see Teilmann et al. (2007) and Sveegaard et al. (2011a).

A previous comparison of satellite tracking data with acoustic porpoise surveys has shown that both methods are indeed representative of harbour por- poise distribution in these waters (Sveegaard et al. 2011b), and consequently the locations from the 34 porpoises were pooled for the analysis. The number of harbour porpoise locations per grid cell (POR) was calculated and used as the response variable in the statistical models.

\section{Data analysis}

Average depth per grid cell (DEP) was calculated in ArcGIS 10 using the 2-min gridded global relief ETOPO2v2 database (http://www.ngdc.noaa.gov/ $\mathrm{mgg} / \mathrm{global} / \mathrm{etopo} 2 \mathrm{html}$ ).

Three statistical analysis methods were used: Mantel test (Mantel 1967, R library 'vegan'), Hurdle analysis (R library 'pscl'; Jackman 2008) and generalized linear models (GLMs; Dobson 2002). All analyses were conducted using R version 2.11.1 (R Development Core Team 2011). 


\section{Mantel test}

A Mantel test is a permutation test that measures the correlation between 2 matrices in order to estimate and adjust for spatial autocorrelation in the data (Mantel 1967). One of the matrices is a Euclidean distance matrix containing the geographical distances between the sample points, here the centres of the grid cells. The other matrix contains the numeric differences between observed densities of herring, mackerel or locations of porpoises in the same locations (averaged over the entire grid cell), or alternatively the difference in average depth. The geographical distances were calculated as the shortest possible swimming distance between grid cell centre points for the marine species. All data were logtransformed to reduce the effect of outliers. The 4 difference matrices were tested one by one against the distance matrix to test for autocorrelation in the data sets.

Partial Mantel tests were used to test for correlation between 2 variables while adjusting for spatial autocorrelation (Legendre 2000). We tested the correlation between the following variables: porpoise-herring, porpoise-depth, porpoise-mackerel, mackerel-herring, mackerel-depth and herringdepth.

\section{Hurdle models}

The relative importance of HER and DEP on POR was tested using a Hurdle model (Zeileis et al. 2008). Hurdle models are useful for analysing variations in count data with a large number of 0 -values, such as the data on porpoise densities used here. They simultaneously fit the distribution of absences and the number of animals in the grid cells where animals are present (Poisson variable). Hurdle models make it possible to study the importance of interactions between main effects, but do not allow for a direct investigation of the effect of the spatial structure (autocorrelation) in the dataset. Instead, a nearest neighbour variable (NNPOR) was included to adjust for autocorrelation in the Hurdle models. The number of harbour porpoise locations was weighted by the area (size of the grid cell) over which they were observed. The independent variables in the model were NNPOR, HER and DEP (HER and DEP were $\log 10$-transformed). The order of reductions in the Hurdle model began with the binomial 0 hurdle part and removed the least significant terms first. After removing non-significant terms in the binomial part, the same procedure was followed for the count model until the most parsimonious model with the lowest possible Akaike information criterion (AIC) was obtained. In order to test the fit of the model, we plotted the predicted versus observed number of porpoises (Appendix 1, Fig. A1).

\section{GLMs}

The relationships between MAC, HER and DEP were examined using a GLM, since MAC was normally distributed and did not contain 0 values. All data were log-transformed prior to analysis, and a mackerel nearest neighbour variable was added to adjust for spatial autocorrelation (NNMAC). Two models were tested: GLM for Gaussian (normally) distributed data and GLM for Poisson distributed data to determine which had the better fit and lowest AIC (Burnham \& Anderson 2004). In order to test the fit of the model we plotted the predicted versus observed number of mackerels (Appendix 1, Fig. A1).

GLM was also conducted on POR in order to ensure that the Hurdle tests were the most appropriate model for explaining the variation in POR when compared to a simple Poisson GLM (Dobson 2002). However, as the Hurdle analysis yielded a better fit $(\mathrm{AIC}=419.6)$ than the GLM Poisson model $(\mathrm{AIC}=$ 526.4) with the same regressors, our results are based on the Hurdle model.

\section{RESULTS}

Inspection of the spatial variation of porpoise locations (POR), mackerel densities (MAC) and herring densities (HER) in the 76 grid cells revealed that all 3 species occurred in high densities around Skagen. However, while POR (Fig. 2A) and HER (Fig. 2C) were found in high numbers in the Kattegat and along the Norwegian Trench, MAC was low in the Kattegat and high in the western Skagerrak (Fig. 2B).

\section{Mantel tests}

We found significant spatial autocorrelation in POR, DEP and MAC but no evidence for spatial autocorrelation in HER on the spatial scale used here (Table 1). POR was strongly associated with areas of high HER, as was MAC. HER was, in turn, closely related to DEP. We found no correlation between 

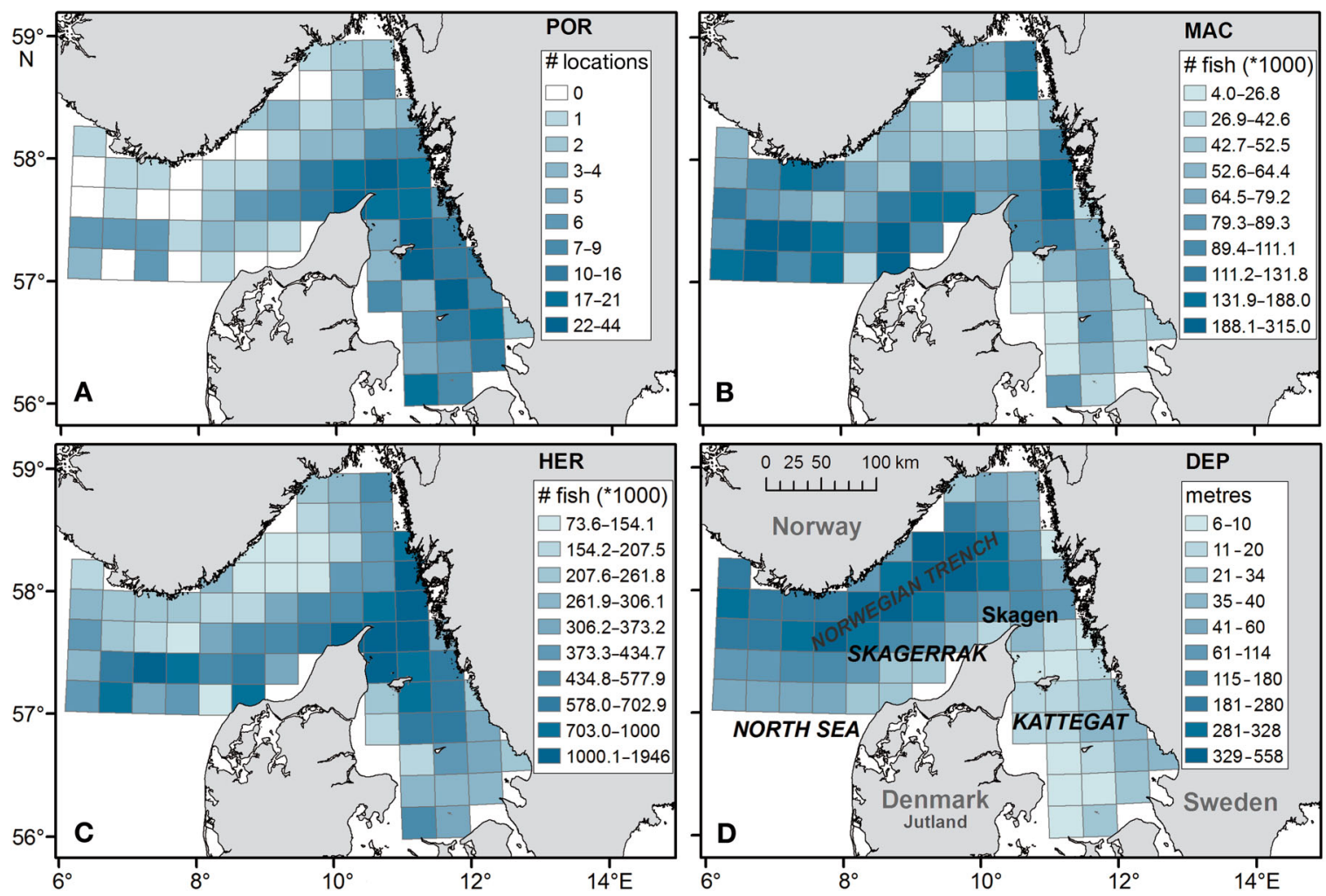

Fig. 2. Hurdle model variables. (A) Number of harbour porpoise locations within each grid cell (POR) pooled for June to August in 1998 to 2009. (B) Mackerel density per grid cell (MAC) based on acoustic surveys and trawls from 2000 to 2009. (C) Herring density per grid cell (HER) based on acoustic surveys and trawls from 2000 to 2009. (D) Average depth per grid cell (DEP) in study area

POR and DEP, MAC and DEP and MAC and POR (Table 1). Correlograms for the number of POR and HER are shown in Appendix 1, Fig. A2.

\section{Hurdle models}

In the binary part of the Hurdle models, POR was only related to NNPOR (Table 2) In the count part, however, POR was related to NNPOR, HER and DEP (Model 1, Table 2), and NNPOR and HER (Model 2, Table 2), respectively. The 2 models were equally parsimonious (similar AIC) and thus accepted as valid models. NNPOR basically described the autocorrelation in porpoise distribution already identified in the Mantel tests. In Model 1, DEP is not significant and, consequently, HER is the only remaining significant variable describing POR. This confirms the results from the Mantel test that only HER was correlated with POR when adjusting for spatial dependency of data.
Table 1. Summary of Mantel and partial Mantel tests examining the spatial autocorrelation within data sets (Mantel tests) and the correlation between data sets while adjusting for spatial autocorrelation (partial Mantel test). Test variables are locations of harbour porpoises (POR), mackerel density (MAC), herring density (HER) and average depth (DEP) per grid cell. Significant values $(p<0.05)$ are shown in bold

\begin{tabular}{|lcc|}
\hline & $Z$ & $\mathrm{p}$ \\
\hline Mantel test & & \\
POR & 0.141 & $\mathbf{0 . 0 0 6 2}$ \\
MAC & 0.0978 & $\mathbf{0 . 0 2 5 3}$ \\
HER & -0.0956 & 0.995 \\
DEP & 0.305 & $\mathbf{0 . 0 0 0 1}$ \\
Partial Mantel test & & \\
POR-HER & 0.2536 & $<\mathbf{0 . 0 0 0 1}$ \\
POR-DEP & 0.02406 & 0.3046 \\
MAC-HER & 0.1895 & $\mathbf{0 . 0 0 1 7}$ \\
MAC-DEP & -0.02871 & 0.7147 \\
MAC-POR & -0.127 & 0.9962 \\
HER-DEP & 0.1868 & $\mathbf{0 . 0 0 0 2}$ \\
& & \\
\hline
\end{tabular}


Table 2. Summary of Hurdle models for describing the distribution of harbour porpoise locations. Model variables are locations of harbour porpoises (POR), nearest neighbour porpoises (NNPOR), herring density (HER) and average depth (DEP). Bin: binary part of data, AIC: Akaike information criterion. ${ }^{*} p<0.05,{ }^{* *} p<0.01,{ }^{* * *} p<0.001$

\begin{tabular}{|c|c|c|}
\hline $\begin{array}{l}\text { Hurdle } \\
\text { ID }\end{array}$ & Model variables & $\mathrm{AIC}$ \\
\hline 1 & $\mathrm{POR} \mathrm{NNPOR}^{* * *}+\mathrm{HER}^{* *}+\mathrm{DEP}+\mathrm{BinNN}^{*}$ & 408.838 \\
\hline 2 & 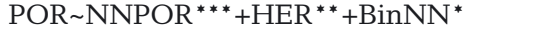 & 408.674 \\
\hline
\end{tabular}

Table 3. Summary of a generalized linear model (GLM) for describing the distribution of mackerel density. Model variables are mackerel density (MAC), nearest neighbour mackerel (NNMAC), herring density (HER), and average depth (DEP). AIC: Akaike information criterion. ${ }^{*} \mathrm{p}<0.05$, ${ }^{* *} \mathrm{p}<0.01,{ }^{* * *} \mathrm{p}<0.001$

\begin{tabular}{|c|c|c|}
\hline $\begin{array}{l}\text { GLM } \\
\text { ID }\end{array}$ & Model variables & AIC \\
\hline $\begin{array}{l}1 \\
\text { (Gaus }\end{array}$ & $\begin{array}{l}\text { MAC } \sim \mathrm{NNMAC}^{* * *}+\mathrm{HER}^{* * *}+\mathrm{DEP}^{* *} \\
\text { sian) }\end{array}$ & 1885.874 \\
\hline $\begin{array}{l}2 \\
\text { (Poiss }\end{array}$ & $\begin{array}{l}\mathrm{MAC} \sim \mathrm{NNMAC}^{* * *}+\mathrm{HER}^{* * *}+\mathrm{DEP}^{* *} \\
\text { on) }\end{array}$ & 1503414.303 \\
\hline
\end{tabular}

\section{GLMs}

MAC were related to NNMAC, HER and DEP in both GLM (Model 1 for Gaussian distribution, Model 2 for Poisson distribution, Table 3). However, the GLM for the Gaussian distributed data was the most parsimonious (lowest AIC), while this model explained $50 \%$ of the variance in MAC.

\section{DISCUSSION}

Harbour porpoises, mackerel and herring did not distribute evenly within the Kattegat and Skagerrak during the studied summer period, and positive relationships were found between porpoises and herring, between mackerel and herring and depth and between herring and depth. Consequently, we accept our hypothesis that harbour porpoises and mackerel were positively related to herring densities, which in turn are positively related to water depth.

This is the first demonstration of a direct relationship between harbour porpoises and a specific prey species. Satellite tracking of harbour porpoises in these waters has revealed a seasonal change in distribution, with porpoises congregating near Skagen and along the Norwegian Trench in the Skagerrak during spring and summer (Sveegaard et al. 2011a). Here, their distribution overlaps with the BSSS herring in June and July, when the herring migrate from the North Sea through the Skagerrak to their spawning sites in the western Baltic (Nielsen et al. 2001). This indicates that porpoise migration may be driven by the arrival of herring in the Skagerrak and that porpoises stay in the area until the herring move south into the Baltic.

We found mackerel density to be related to herring distribution and depth. The majority of mackerel $(89 \%)$ in the acoustic surveys were medium-sized fish of 20 to $30 \mathrm{~cm}$. Mackerel of this size are 0 to $2 \mathrm{yr}$ old and prey on small fish $(<10 \mathrm{~cm}$, primarily herring) and crustaceans (primarily the copepod Calanus finmarchicus; Dahl \& Kirkegaard 1986). C. finmarchicus is also a primary prey of herring (Corten 2001, Broms et al. 2012), and prey competition between these 2 species has previously been suggested (Prokopchuk $\&$ Sentyabov 2006). The relationship found between mackerel and herring may thus combine mackerel preying directly on herring, and their simultaneous competition with herring for copepods. The spatial distribution and dietary preferences of mackerel and herring were recently studied in the Norwegian Sea (Langøy et al. 2012). There, only limited overlap between the 2 species and no predation of mackerel on herring were found, suggesting that drivers for mackerel distribution may change both spatially and temporally.

Both mackerel and herring densities are correlated with depth, and their distributions correspond to 2 major upwelling zones: the Northern Kattegat front, which separates the surface water in a strong salinity gradient between the Kattegat (26\%) and Skagerrak water $(34 \%)$, and the Norwegian Trench, representing a steep drop from about 100 to $700 \mathrm{~m}$ in depth (Danielssen et al. 1997, Jakobsen 1997). Both areas are biologically productive with enhanced primary production due to upwelling of nutrients (Pingree et al. 1975, Wolanski \& Hamner 1988), making the areas attractive for marine predators like the harbour porpoise. Aggregations of fish and harbour porpoises have previously been found in connection to oceanic fronts. In the north-western North Sea, herring prefer zooplankton-rich waters at depths between 100 and $150 \mathrm{~m}$ (Maravelias et al. 2000). Johnston et al. (2005) examined the movement of 6 satellite tagged harbour porpoises in the Bay of Fundy and found that they preferred regions with strong currents, where prey aggregate in large numbers. Skov \& Thomsen (2008) found that small- 
scale changes in local currents caused by tidal currents in an area with steep changes in bathymetry were the main factors associated with porpoise presence. They further suggested that feeding at predictable frontal structures with increased prey availability may be a beneficial foraging strategy, as it reduces the foraging area of the porpoises. It would have been interesting to include variables representing fronts and currents in our study, but since data were pooled over 3 mo in order to obtain sufficient harbour porpoise location data, this was not feasible. Furthermore, pooling of data on currents and fronts over a longer time span makes little sense, as these factors may change daily.

The choice of spatial and temporal scale may affect our results since prey and predator patchiness may change over different scales. For instance, Bailey \& Thompson (2009) found that porpoise distribution was only significantly related to the environmental variables sand, distance to coast and depth when these were measured on a grid scale of $1 \times 1 \mathrm{~km}$ and $2 \times 2 \mathrm{~km}$, but not on a $4 \times 4 \mathrm{~km}$ grid scale. Optimally, different scales should be included in the models. In this study, however, the spatial coverage of the acoustic surveys was planned for large-scale estimation of fish abundance, which made analysis on smaller spatial scales impossible. Nevertheless, since herring, mackerel and harbour porpoises move several thousand kilometres every year, their spatial distribution is likely to be associated with environmental features that can be measured at this scale.

Temporal scale (resolution in time) is another influential factor since variations in climatic factors, weather conditions and prey movement from year to year may cause a temporal shift in the onset of herring migration (Broms et al. 2012). However, this study was restricted by the number of harbour porpoise satellite locations, which would be inadequate for comparing shorter time intervals.

The results of this study are only applicable to the summer season and probably only within the defined study area because variables determining the presence of prey may change according to prey species, area, season and even spatial scale. Still, the positive correlation found between the distribution of 2 marine predators and 1 of their prey species gives us a unique insight into the tight coupling between predators, prey and the spatial distribution of environmental variables. Clearly, herring densities do explain a substantial part of the variation in the summer distribution of harbour porpoises at the studied spatial scale. The relationship between densities of mackerel and herring is less evident, and the influ- ence and distribution of their common prey species Calanus finmarchicus needs to be examined further.

Our results may allow for implementation of system-oriented management of marine mammals and fish. The highest number of porpoise locations was found near Skagen, and in 2010, this area was designated as a 'Special Area of Conservation' for harbour porpoises according to the EC Habitat Directive (92/43/EEC). Based on our findings, we advocate that the management of harbour porpoises should include monitoring and management of important prey species. This will be in concordance with the EU Marine Strategy Framework Directive (adopted in June 2008; 2008/56/EC) aiming to protect the marine environment across Europe and to achieve good environmental status of the EU's marine waters by 2020 by adopting an ecosystem management approach. Simultaneous monitoring of predator and prey will further aid the understanding of their interactions and influence on each other's distribution. More research is needed to fully understand the predator-prey relationship between harbour porpoise, mackerel and herring. However, our findings provide new insight into the interplay between 2 important marine predators and their prey, and other similar studies might help uncover the ecological complexity underlying the distribution of marine species.

Acknowledgements. We are grateful to everyone who helped with data collection, both with the satellite tagging of harbour porpoises and the acoustic herring surveys, particularly R. Dietz, J. Tougaard and S. Edrén from Aarhus University (AU), and B. Lundgren from DTU Aqua. We thank C. Mohn (AU) for providing bathymetry data, K. Dahl (AU) for advice and information on interactions between mackerel and herring and M. Langer Andersen (GEUS) for help with spatial illustrations. Twenty-eight of the satellite tagged porpoises were tagged as part of a joint project between the Danish Institute for Fisheries Research, the Fjord and Belt Centre, AU and University of Southern Denmark in the years 1998 to 2002, and 6 were tagged as part of cooperation between AU and U. Siebert at the University of Kiel, Research and Technology Centre (FTZ) in 2003 to 2009. The study was carried out under permission from the Danish Forest and Nature Agency (SN 343/SN-0008) and the Animal Welfare Division (Ministry of Justice, 1995-101-62). We also thank the anonymous reviewers, whose suggestions and comments greatly improved this paper.

\section{LITERATURE CITED}

Aarefjord H, Bjørge A, Kinze CC, Lindstedt I (1995) Diet of the harbour porpoise Phocoena phocoena in Scandinavian waters. Rep Int Whaling Comm Spec Issue Ser 16: 211-222

Bailey H, Thompson (2009) Using marine mammal habitat modelling to identify priority conservation zones within a 
marine protected area. Mar Ecol Prog Ser 378:279-287

Benke H, Siebert U, Lick R, Bandomir B, Weiss R (1998) The current status of harbour porpoises (Phocoena phocoena) in German waters. Arch Fish Mar Res 46:97-123

> Börjesson P, Berggren P, Ganning B (2003) Diet of harbour porpoises in the Kattegat and Skagerrak Seas: accounting for individual variation and sample size. Mar Mamm Sci 19:38-58

> Broms C, Melle W, Horne JK (2012) Navigation of herring feeding migration: the role of ecological gradients on an oceanic scale. Mar Biol Res 8:461-474

Burnham KP, Anderson DR (2004) Multimodel inference understanding AIC and BIC in model selection. Sociol Methods Res 33:261-304

> Corten A (2001) Northern distribution of North Sea herring as a response to high water temperatures and/or low food abundance. Fish Res 50:189-204

Dahl K, Kirkegaard E (1986) Stomach content of mackerel, horse mackerel and whiting in the eastern part of the North Sea in July 1985. ICES C.M.1986/H:86. ICES, Copenhagen

> Danielssen DS, Edler L, Fonselius S, Hernroth L, Ostrowski M, Svendsen E, Talpsepp L (1997) Oceanographic variability in the Skagerrak and Northern Kattegat, MayJune, 1990. ICES J Mar Sci 54:753-773

Dobson AJ (2002) An introduction to generalized linear models. Chapman \& Hall/CRC, Boca Raton, FL

> Edrén SMC, Wisz MS, Teilmann J, Dietz R, Söderkvist J (2010) Modelling spatial patterns in harbour porpoise satellite telemetry data using maximum entropy. Ecography 33:698-708

Embling CB, Gillibrand PA, Gordon J, Shrimpton J, Stevick PT, Hammond PS (2010) Using habitat models to identify suitable sites for marine protected areas for harbour porpoises (Phocoena phocoena). Biol Conserv 143:267-279

Gilles A, Adler S, Kaschner K, Scheidat M, Siebert U (2011) Modelling harbour porpoise seasonal density as a function of the German Bight environment: implications for management. Endang Species Res 14:157-169

Hamre J (1978) The effect of recent changes in the North Sea mackerel fishery on stock and yield. Rapp P-V Reùn Cons Int Explor Mer 172:197-210

ICES (International Council for the Exploration of the Sea (2009) Report of the working group on mackerel and horse mackerel egg surveys (WGMEGS). ICES CM 2009/LRC:09. ICES, Copenhagen

Jackman S (2008) pscl: classes and methods for R developed in the Political Science Computational Laboratory, Stanford University. Department of Political Science, Stanford University, Stanford, CA. R package version 0.95 . http://CRAN.R-project.org/package $=$ pscl

> Jakobsen F (1997) Hydrographic investigation of the Northern Kattegat front. Cont Shelf Res 17:533-554

Jansen T, Gislason H (2011) Temperature affects the timing of spawning and migration of North Sea mackerel. Cont Shelf Res 31:64-72

Johnston DW, Westgate AJ, Read AJ (2005) Effects of finescale oceanographic features on the distribution and movements of harbour porpoises Phocoena phocoena in the Bay of Fundy. Mar Ecol Prog Ser 295:279-293

> Koopman HN (1998) Topographical distribution of the blubber of harbor porpoises (Phocoena phocoena). J Mammal 79:260-270

> Langøy H, Nøttestad L, Skaret G, Broms C, Fernö A (2012) Overlap in distribution and diets of Atlantic mackerel
(Scomber scombrus), Norwegian spring-spawning herring (Clupea harengus) and blue whiting (Micromesistius poutassou) in the Norwegian Sea during late summer. Mar Biol Res 8:442-460

> Lawson JW, Magalhães AM, Miller EH (1998) Important prey species of marine vertebrate predators in the northwest Atlantic: proximate composition and energy density. Mar Ecol Prog Ser 164:13-20

Legendre P (2000) Comparison of permutation methods for the partial correlation and partial Mantel tests. J Stat Comput Simulation 67:37-73

- Mantel N (1967) The detection of disease clustering and a generalized regression approach. Cancer Res 27: 209-220

> Maravelias CD, Reid DG, Simmonds EJ, Haralabous J (1996) Spatial analysis and mapping of acoustic survey data in the presence of high local variability: geostatistical application to North Sea herring (Clupea harengus). Can J Fish Aquat Sci 53:1497-1505

> Maravelias CD, Reid DG, Swartzman G (2000) Seabed substrate, water depth and zooplankton as determinants of the prespawning spatial aggregation of North Atlantic herring. Mar Ecol Prog Ser 195:249-259

Marubini F, Gimona A, Evans PGH, Wright PJ, Pierce GJ (2009) Habitat preferences and interannual variability in occurrence of the harbour porpoise Phocoena phocoena off northwest Scotland. Mar Ecol Prog Ser 381:297-310

> Nielsen JR, Lundgren B, Jensen TF, Staehr KJ (2001) Distribution, density and abundance of the western Baltic herring (Clupea harengus) in the Sound (ICES Subdivision 23) in relation to hydrographical features. Fish Res 50: 235-258

Palka D (1995) Influences on spatial patterns of Gulf of Maine harbor porpoises. In: Blix AS, Walløe L, Ulltang Ø (eds) Whales, seals, fish and man. Elsevier Science, Amsterdam, p 69-75

> Pingree RD, Pugh PR, Holligan PM, Forster GR (1975) Summer phytoplankton blooms and red tides along tidal fronts in the approaches to the English Channel. Nature 258:672-677

Postuma KH (1965) Some remarks on the mackerel migration in the North Sea. ICES CM 1965. ICES, Copenhagen

Prokopchuk I, Sentyabov E (2006) Diets of herring, mackerel, and blue whiting in the Norwegian Sea in relation to Calanus finmarchicus distribution and temperature conditions. ICES J Mar Sci 63:117-127

R Development Core Team (2011) R: a language and environment for statistical computing. R Foundation for Statistical Computing, Vienna. Available at www.R-project.org

> Read AJ, Westgate AJ (1997) Monitoring the movements of harbour porpoises (Phocoena phocoena) with satellite telemetry. Mar Biol 130:315-322

Rose GA, Leggett WC (1990) The importance of scale to predator prey spatial correlations: an example of Atlantic fishes. Ecology 71:33-43

Santos MB, Pierce GJ (2003) The diet of harbour porpoise (Phocoena phocoena) in the northeast Atlantic. Oceanogr Mar Biol Annu Rev 41:355-390

Simmonds EJ, Toresen R, Corten A, Pedersen J, Reid DG, Fernandes PG, Hammer C (1996) 1995 ICES coordinated acoustic survey of ICES divisions IVa, IVb \& VIa. ICES CM 1995/H:8. ICES, Copenhagen

Skov H, Thomsen F (2008) Resolving fine-scale spatiotemporal dynamics in the harbour porpoise Phocoena 
phocoena. Mar Ecol Prog Ser 373:173-186

Spitz J, Mourocq E, Schoen V, Ridoux V (2010) Proximate composition and energy content of forage species from the Bay of Biscay: high- or low-quality food? ICES J Mar Sci 67:909-915

Sveegaard S, Teilmann J, Tougaard J, Dietz R, Mouritsen KN, Desportes G, Siebert U (2011a) High-density areas for harbor porpoises (Phocoena phocoena) identified by satellite tracking. Mar Mamm Sci 27:230-246

Sveegaard S, Teilmann J, Berggren P, Mouritsen KN, Gillespie D, Tougaard J (2011b) Acoustic surveys confirm areas of high harbour porpoise density found by satellite tracking. ICES J Mar Sci 68:929-936

Sveegaard S, Andreasen H, Mouritsen KN, Jeppesen JP, Teilmann J, Kinze CC (2012) Correlation between the seasonal distribution of harbour porpoises and their prey in the Sound, Baltic Sea. Mar Biol 159:1029-1037

Swartzman G, Stuetzle W, Kulman K, Powojowski M (1994) Relating the distribution of pollock schools in the Bering Sea to environmental factors. ICES J Mar Sci 51:481-492

Teilmann J, Larsen F, Desportes G (2007) Time allocation and diving behaviour of harbour porpoises (Phocoena phocoena) in Danish and adjacent waters. J Cetacean Res Manag 9:201-210

Williams TM, Estes JA, Doak DF, Springer AM (2004) Killer appetites: assessing the role of predators in ecological communities. Ecology 85:3373-3384

Wolanski E, Hamner WM (1988) Topographically controlled fronts in the ocean and their biological influence. Science 241:177-181

Zeileis A, Kleiber C, Jackman S (2008) Regression models for count data in R. J Stat Softw 27:1-2

Appendix 1. Evaluation of model fits and autocorrelation structure
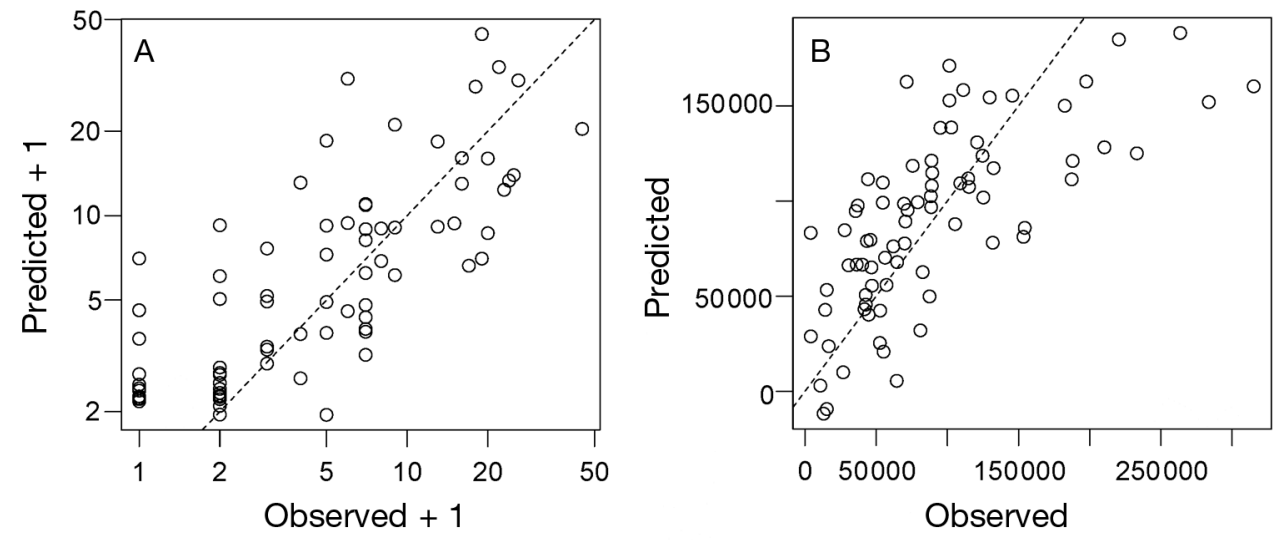

Fig. A1. Phocoena phocoena and Scomber scombrus. Predicted number of observations vs. observed number of observations per quarter ICES square displaying (A) number of harbour porpoises predicted with the Hurdle test (formula $=$ POR NNPOR + HER + DEP) and (B) number of mackerel predicted with the generalized linear model (MAC $\sim$ NNMAC + HER $+\mathrm{DEP}$, family $=$ Gaussian). The predicted and observed numbers of porpoises were highly correlated (Pearson $\mathrm{r}=0.64$; Spearman rho $=0.76$ ), and the same was true for mackerel (Pearson $r=0.71$; Spearman rho $=0.76$ )
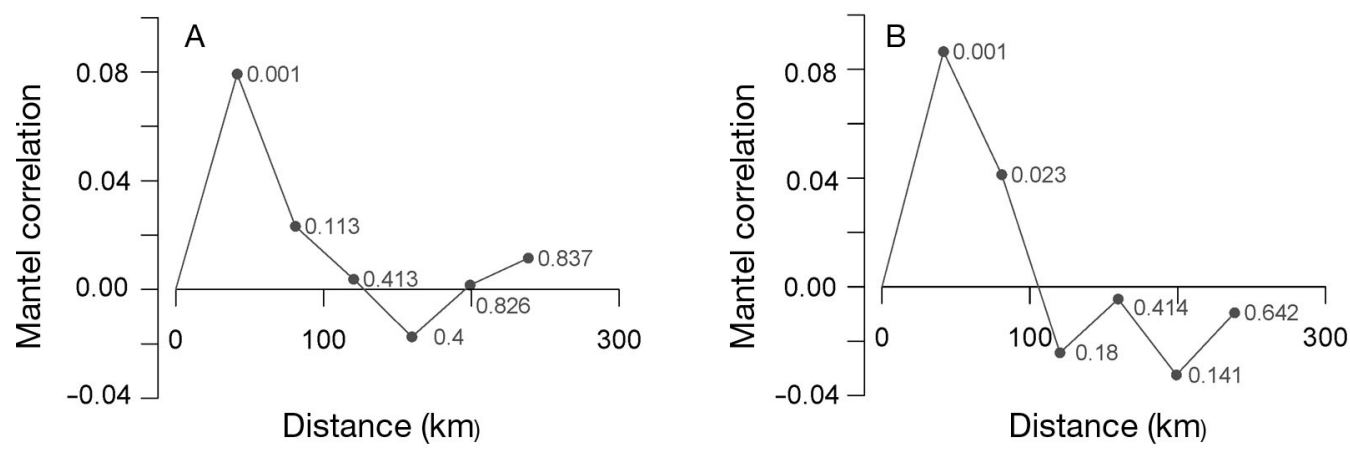

Fig. A2. Phocoena phocoena and Scomber scombrus. Correlograms for (A) harbour porpoise and (B) herring. Significance levels for Pearson correlations at different lag distances are indicated by each point 